\title{
Triptolide sensitizes human breast cancer cells to tumor necrosis factor- $\alpha$-induced apoptosis by inhibiting activation of the nuclear factor- $\kappa B$ pathway
}

\author{
XIAOLI CHENG ${ }^{1,2^{*}}$, WENLI SHI ${ }^{3 *}$, CANGUO ZHAO $^{1}$, DAN ZHANG $^{1}$, PIAO LIANG ${ }^{1}$, GUOHUI WANG $^{4}$ and LI LU ${ }^{1}$ \\ ${ }^{1}$ Department of Pathophysiology, Guangzhou Medical University, Guangzhou, Guangdong 511436; \\ ${ }^{2}$ Department of Pathology, Hubei University of Medicine, Shiyan, Hubei 442000; ${ }^{3}$ Department of Pathology, \\ Guangzhou Nansha Central Hospital, Guangzhou First Municipal People's Hospital, Guangzhou, Guangdong 510180; \\ ${ }^{4}$ Department of Internal Medicine, Henan Cancer Hospital, The Affiliated Cancer Hospital of Zhengzhou University, \\ Zhengzhou, Henan 450008, P.R. China
}

Received February 14, 2015; Accepted December 3, 2015

DOI: $10.3892 / \mathrm{mmr} .2016 .4931$

\begin{abstract}
Tumor necrosis factor- $\alpha$ (TNF- $\alpha)$ can act as either a tumor promoter, linking inflammation with carcinogenesis, or a tumor inhibitor, inducing cancer cell death. However, several types of cancer, including breast cancer, are resistant to TNF- $\alpha$ therapy. Triptolide, a diterpene triepoxide, has been reported to exert anti-inflammatory and antiproliferative effects, associated with the inhibition of nuclear factor $-\kappa \mathrm{B}(\mathrm{NF}-\kappa \mathrm{B})$. The present study investigated the effects of triptolide sensitization on human breast cancer cells to TNF- $\alpha$-induced apoptosis by inhibiting activation of the NF- $\kappa \mathrm{B}$ pathway. Human breast cancer MDA-MB-231 cells and MCF-7 cells were treated with different concentrations of triptolide, with or without $10 \mathrm{ng} / \mathrm{ml} \mathrm{TNF}-\alpha$, for different durations, followed by measurement of cell proliferation using a 3-[4,5-dimethyltiazol-2-yl]-2.5-diphenyl-tetrazolium bromide assay, apoptosis induction, through determination of caspase- 3 activity and poly (ADP-ribose) polymerase (PARP) cleavage, and $\mathrm{NF}-\kappa \mathrm{B}$ pathway activation, through determination of inhibitor of $\mathrm{NF}-\kappa \mathrm{B}(\mathrm{I} \kappa \mathrm{B})$ and the $\mathrm{NF}-\kappa \mathrm{B}$ downstream genes, $\mathrm{X}$-linked inhibitor of apoptosis protein (XIAP) and cellular inhibitor of apoptosis protein1/2 (cIAP1/2)] using Western blot and reverse transcription-quantitative polymerase chain
\end{abstract}

Correspondence to: Dr Li Lu, Department of Pathophysiology, Guangzhou Medical University, B2 Jingxiu Road, Guangzhou, Guangdong 511436, P.R. China

E-mail: 925295339@qq.com

Dr Guohui Wang, Department of Internal Medicine, Henan Cancer Hospital, The Affiliated Cancer Hospital of Zhengzhou University, 127 Dongming Road, Zhengzhou, Henan 450008, P.R. China E-mail:wgh3001@qq.com

${ }^{*}$ Contributed equally

Key words: cancer therapy, tumor necrosis factor- $\alpha$, triptolide reaction analyses. TNF- $\alpha$, when combined with triptolide, was observed to inhibit the activation of $\mathrm{I} \kappa \mathrm{B} \alpha$, increase the level of cleaved PARP, and further activate caspase-3 in the breast cancer cells. Triptolide also inhibited the expression levels of the downstream anti-apoptotic genes of NF- $\kappa \mathrm{B}$ activation, XIAP and cIAP1/2. The results of the present study demonstrated that triptolide sensitized human breast cancer cells to TNF- $\alpha$-induced apoptosis, which may provide a promising combination strategy for human breast cancer therapeutics.

\section{Introduction}

Breast cancer is the second leading cause of cancer-associated mortality, with high morbidity and mortality rates in women worldwide. Chemotherapy remains an alternative therapeutic option for breast cancer to surgery and radiation, however, multidrug resistance and an unfavorable systemic toxicity against normal cells limit their clinical effects, which highlights the urgent requirement to identify novel therapeutic strategies and agents (1).

Tumor necrosis factor- $\alpha(\mathrm{TNF}-\alpha)$ is one of the major inflammatory cytokines, which can act as either a tumor promoter, by linking inflammation with carcinogenesis, or as a tumor inhibitor, through the induction of cancer cell death. TNF- $\alpha$ signaling occurs via two cell-surface receptors, TNF- $\alpha$ factor receptor 1 and 2 (TNFR1 and TNFR2). Complex I is formed when TNF- $\alpha$ binds to TNFR-1, and this event leads to activation of nuclear factor $(\mathrm{NF})-\kappa \mathrm{B}$, mitogen-activated protein kinases and Complex II, ultimately leading to apoptosis $(2,3)$. Of note, Complex I and Complex II have disparate and opposing effects on apoptosis. Complex I leads to activation of the NF- $\kappa \mathrm{B}$ signaling pathway, whereas Complex II leads to activation of caspase-3 and caspase-9. Activated NF- $\kappa$ B can upregulate the expression levels of downstream genes, which include anti-apoptotic genes, including X-linked inhibitor of apoptosis (XIAP) and cellular inhibitors of apoptosis 1 and 2 (cIAP1/2). Therefore, the balance between Complex I and Complex II results in cell resistance to TNF- $\alpha$-mediated apoptosis. In the tumor microenvironment, sustained $\mathrm{NF}-\kappa \mathrm{B}$ 
activation can have an anti-apoptotic effect on tumor cells, which depends on Complex I signaling, whereas Complex II can attenuate TNF- $\alpha$-induced $N F-\kappa B$ activation.

Triptolide, a natural and biologically active compound as a diterpenoid triepoxide, was originally purified from the Chinese herb Tripterygium wilfordii Hook F (4). This natural product has been used in traditional Chinese medicine for centuries, and has a myriad of therapeutic applications against inflammation and autoimmune diseases $(5,6)$. Previous studies have reported that triptolide has antitumor, anti-inflammatory and immunosuppressive activities. In particular, triptolide has been investigated for several different types of cancer cells in vitro and in vivo (7-9). The inhibitory effects of triptolide in the growth of cholangiocarcinoma cells in hamsters (10), and the growth of xenografts in human breast cancer, bladder cancer, melanoma and gastric carcinoma, have been shown in nude mice (9). It has also been demonstrated that the antiproliferative properties of triptolide may be involved in inhibiting $\mathrm{NF}-\kappa \mathrm{B}$ activity and inducing cell apoptosis (11). Taken together, these previous studies have demonstrated that triptolide may be clinically effective for tumor chemotherapy.

The TNF- $\alpha$ signaling pathway is important in tumor development, and its antitumor properties may be exploited with avoidance of its tumorigenic properties (2). Based on the essential requirement for an inflammatory microenvironment in tumor formation, the present study hypothesized that triptolide sensitizes human breast cancer cells to TNF- $\alpha$-induced apoptosis by inhibiting activation of the NF- $\kappa$ B pathway. The results of the present study demonstrated that TNF- $\alpha$ combined with triptolide effectively sensitized human breast cancer cells to triptolide-mediated induction of apoptosis, by targeting inhibitor of $\mathrm{NF}-\kappa \mathrm{B}(\mathrm{I} \kappa \mathrm{B})$, an effective signaling pathway of TNF- $\alpha$. Due to the inhibitory activities of $I_{\kappa} B$, triptolide inhibited the $\mathrm{NF}-\kappa \mathrm{B}$ signaling pathway and further promoted the activation of caspase-3. Finally, increased activation of caspase- 3 resulted in apoptosis, which contributed to its anti-inflammatory and anticancer activities. These observations suggested that this may be a promising combination strategy for use in human breast cancer therapeutics.

\section{Materials and methods}

Reagents. Triptolide was purchased from A.G. Scientific, Inc. (San Diego, CA, USA) and dissolved in dimethyl sulfoxide (DMSO; Sigma-Aldrich, St. Louis, MO, USA). Stock solutions $(50 \mathrm{mM})$ were prepared, and aliquots were stored at $-20^{\circ} \mathrm{C}$ for further use in the subsequent experiments. L15/1640, penicillin and streptomycin were purchased from Invitrogen (Thermo Fisher Scientific, Inc., Waltham, MA, USA). Fetal bovine serum (FBS) was obtained from Gibco (Thermo Fisher Scientific, Inc). 3-[4,5-dimethyltiazol-2-yl]-2.5-diphenyl-tetrazolium bromide (MTT; BTN111105), RNaseA and reverse transcription-quantitative polymerase chain reaction (RT-qPCR) kits were purchased from Promega Corporation (San Luis Obispo, CA, USA). Ac-Asp-Glu-Val-Asp-AMC and Z-Gly-Gly-Leu-AMC, the substrates for caspase-3 and chymotrypsin (CT)-like activities, respectively, were obtained from Calbiochem, Inc. (San Diego, CA, USA). Mouse monoclonal anti-poly(ADP-ribose)polymerase (PARP) (46D11; dilution, 1:1,000), anti-caspase-3 (8G10; dilution, 1:1,000); anti-caspase-9 (9502; dilution, 1:1,000), anti-XIAP (2042; dilution, 1:1,000) and anti-IAP1/2 (4952; dilution, 1:1,000) were purchased from Cell Signaling Technology, Inc. (Danvers, MA, USA). Mouse monoclonal anti-ubiquitin (P4D1; sc-8017; dilution, 1:1,000), rabbit polyclonal anti-IкB- $\alpha$ (C-15; sc-203; dilution, 1:1,000), goat polyclonal anti- $\beta$-actin $(\mathrm{C}-11$; sc-1615; dilution, 1:5,000), and secondary goat anti-rabbit IgG-horseradish peroxidase (dilution, 1:5,000; sc-2054) were purchased from Santa Cruz Biotechnology, Inc. (Santa Cruz, CA, USA). Velcade was purchased from A.G. Scientific, Inc..

Cell culture and whole cell extract preparation. Human breast cancer MDA-MB-231 and MCF-7 cells were obtained from the American Type Culture Collection (Manassas, VA, USA) and grown in L15/1640 supplemented with $10 \% \mathrm{FBS}, 100 \mathrm{U} / \mathrm{ml}$ penicillin and $100 \mu \mathrm{g} / \mathrm{ml}$ streptomycin $\left(5.0-8.0 \times 10^{5}\right.$ cells $\left./ \mathrm{ml}\right)$. All cells were maintained at $37^{\circ} \mathrm{C}$ with $5 \% \mathrm{CO}_{2}$. Whole cell extracts were prepared, as described previously $(12,13)$. Briefly, cells were harvested, washed with phosphate-buffered saline (PBS) and homogenized for $30 \mathrm{~min}$ at $4^{\circ} \mathrm{C}$ in lysis buffer, containing $50 \mathrm{mM}$ Tris- $\mathrm{HCl}$ (pH 7.5), $150 \mathrm{mM} \mathrm{NaCl}, 0.5 \%$ NP-40, $0.5 \mathrm{mM}$ phenylmethylsulfonyl fluoride and $0.5 \mathrm{mM}$ dithiothreitol (Invitrogen; Thermo Fisher Scientific, Inc.). The lysates were immediately centrifuged at $12,000 \mathrm{x}$ g for 12 min at $4^{\circ} \mathrm{C}$, and the supernatants were collected as whole cell extracts. Protein concentration was determined using a bicinchoninic acid protein assay (Pierce Biotechnology, Rockford, IL, USA). Bovine serum albumin (BSA) was used as a standard (Invitrogen; Thermo Fisher Scientific, Inc.).

MTT assay. MTT assays were performed in 96-well plates. Briefly, 3.5x105 MDA-MB-231/MCF-7 cells were seeded per well and incubated overnight at $37^{\circ} \mathrm{C}$. The cells were treated with triptolide $(13,25,50,100,200$ or $400 \mathrm{~nm})$, alone or in combination with TNF- $\alpha(10 \mathrm{ng} / \mathrm{ml})$ for $48 \mathrm{~h}$. DMSO $(0.1 \%)$-treated cells were used as a control. Inhibition of cell proliferation was determined using an MTT assay (10 $\mu \mathrm{l}$ MTT/100 $\mu$ l cells), as described previously (12). Absorbance was measured using a Wallac Victor $3^{\mathrm{TM}}$ multilabel counter (PerkinElmer, Walltham, MA, USA) at $540 \mathrm{~nm}$, and cell viability was determined relative to the DMSO-treated control cells. In individual experiments, each treatment condition was set up with four repeats, and each experiment was repeated three times independently.

Caspase-3 activity determination, CT-like activity assay and Western blot analysis. Caspase-3 activity was determined by measuring the release of the AMC groups from the caspase-3-specific substrate, Ac-Asp-Glu-Val-Asp-AMC. The MDA-MB-231/MCF-7 cells (5.0-8.0×10\%/well) were plated and, following overnight incubation at $37^{\circ} \mathrm{C}$, were treated with indicated concentrations of triptolide, either alone or in combination with TNF- $\alpha(10 \mathrm{ng} / \mathrm{ml})$, for $24 \mathrm{~h}$, followed by preparation of whole cell extracts. The cell extracts $(25 \mathrm{mg})$ were then incubated in a 96-well plate in $100 \mu \mathrm{l}$ assay buffer $(50 \mathrm{mM}$ Tris-HCl; pH 7.5) with $40 \mu \mathrm{M}$ Ac-Asp-Glu-Val-Asp-AMC. The reaction mixture was incubated at $37^{\circ} \mathrm{C}$ for $2 \mathrm{~h}$ and the hydrolyzed fluorescent AMC groups were quantified, as previously described $(12,13)$. The production of AMC groups was measured using a Victor3 Multilabel Counter (PerkinElmer) 
A

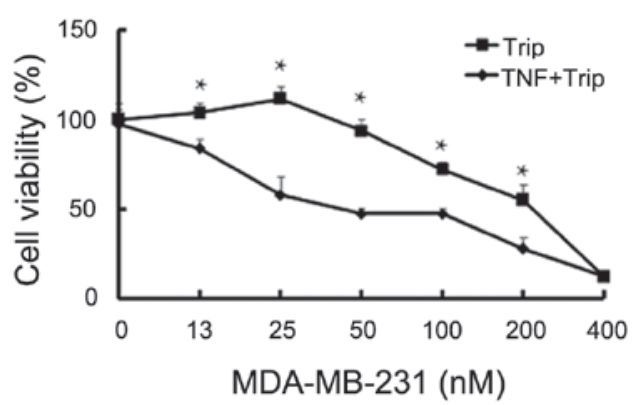

B

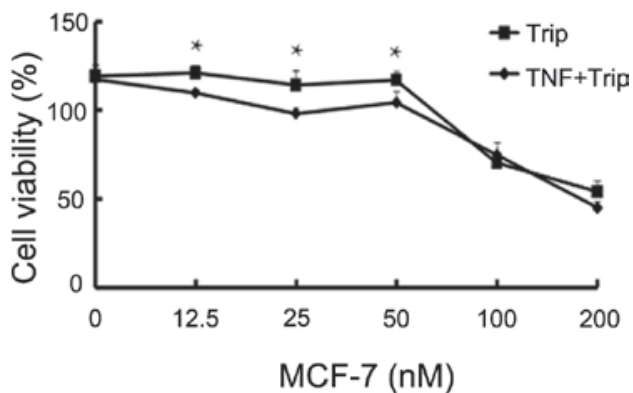

Figure 1. Effect of dose on TNF- $\alpha+$ triptolide on cell viability. (A) MDA-MB-231 cells and (B) MCF-7 cells were treated either with different concentrations of triptolide, or with TNF- $\alpha(10 \mathrm{ng} / \mathrm{ml})$ and different concentrations of triptolide for $48 \mathrm{~h}$, followed by measurement of cell viability using a 3-[4,5-dimethyltiazol-2-yl]-2.5-diphenyl-tetrazolium bromide assay. MDA-MB-231 cells: IC50 triptolide=209 nM; IC50 triptolide+TNF- $\alpha=131 \mathrm{nM}$. MCF-7 cells: IC50 triptolide $=171 \mathrm{nM}$; IC50 triptolide+TNF- $\alpha=153 \mathrm{nM}$. Data are expressed as the mean \pm standard deviation of three experiments. *P $<0.05$. TNF- $\alpha$, tumor necrosis factor- $\alpha$; Trip, triptolide; IC50, half maximal inhibitory concentration.

with an excitation filter of $380 \mathrm{~nm}$ and an emission filter of $460 \mathrm{~nm}$.

Proteasomal CT-like activity was determined by measuring the release of the AMC groups from the CT-like specific substrate, Z-Gly-Gly-Leu-AMC. The MDA-MB-231 and MCF-7 cells (5.0-8.0x10\%/well) were plated in 96-well plates and treated with triptolide at the desired final concentrations, either alone or in combination of TNF- $\alpha(10 \mathrm{ng} / \mathrm{ml})$, for $8 \mathrm{~h}$, or for the indicated time periods, and incubated with Z-Gly-Gly-Leu-AMC (at $40 \mu \mathrm{M}$ ) for an additional $2 \mathrm{~h}$ at $37^{\circ} \mathrm{C}$. The production of hydrolyzed AMC groups was measured, as previously described $(12,13)$.

For Western blot analysis, the cells $\left(5.0-8.0 \times 10^{5} / \mathrm{ml}\right)$ were plated in $60 \mathrm{~mm}$ dishes and treated with the desired final concentration of triptolide, either alone or in combination with TNF- $\alpha$, for different time periods, followed by preparation of whole cell extracts. Protein was extracted from the whole cell lysates using radioimmunoprecipitation assay buffer (Beyotime Institute of Biotechnology, Haimen, China) supplemented with $10 \mathrm{mM} \beta$-glycerophosphate, $1 \mathrm{mM}$ sodium orthovanadate, $10 \mathrm{mM} \mathrm{NaF}, 1 \mathrm{mM}$ phenylmethylsulfonyl fluoride and 1X Roche Complete Mini Protease Inhibitor Cocktail (Roche Diagnostics, Indianapolis, IN, USA). After the determination of protein concentration, $5 \mu \mathrm{g}$ protein extracted from cultured cells was separated by sodium dodecyl sulfate polyacrylamide gel electrophoresis and electrically transferred onto polyvinylidene difluoride membranes. The blots were blocked with 5\% fat milk for $1 \mathrm{~h}$ at room temperature, and then incubated with specific antibodies for $1 \mathrm{~h}$ at room temperature. After washing, membranes were incubated for $1 \mathrm{~h}$ at room temperature with goat anti-rabbit IgG-horseradish peroxidase and exposed to X-ray film. Western blots were analyzed using enhanced chemiluminescence reagent (Santa Cruz Biotechnology, Inc.), as previously described $(12,13)$.

$R T-q P C R$. Cells $\left(5 \times 10^{6}\right)$ were pretreated with TNF- $\alpha(10 \mathrm{ng} / \mathrm{ml})$ at the desired final concentrations, either alone or in combination of triptolide for $12 \mathrm{~h}$ at $37^{\circ} \mathrm{C}$. Total RNA was extracted using TRIzol reagent $\left(5 \times 10^{6}\right.$ cells $/ \mathrm{ml}$; Invitrogen; Thermo Fisher Scientific, Inc.), according to the manufacturer's protocol. The genomic DNA was digested using RNase-free DNaseI, and the concentration of the RNA was detected using UV spectroscopy as previously described (12). Single-stranded
cDNA was generated using random hexamer primers with a Prime Script ${ }^{\circledR}$ RT Master mix first strand synthesis system for RT-qPCR (A1250; Promega Corporation). Following RT, qPCR was performed with $\mathrm{SYBR}^{\circledR}$ Premix Ex Taq ${ }^{\mathrm{TM}}$ II (Tli RNaseH Plus). The $20.0 \mu \mathrm{l}$ reaction mixture contained $2.0 \mu \mathrm{l}$ cDNA template, $10.0 \mu 1 \mathrm{SYBR}^{\circledR}$ Premix Ex Taq ${ }^{\mathrm{TM}}$ II $(2 \mathrm{x})$, $0.8 \mu \mathrm{l}$ PCR forward primer, $0.8 \mu \mathrm{l}$ PCR reverse primer, $0.4 \mu \mathrm{l}$

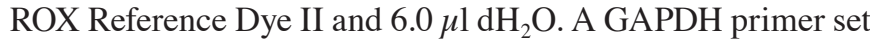
was used as an internal control. The products were detected by agarose gel electrophoresis. The PCR primers used were as follows: XIAP, forward ACATGGCTGTCAAGAAGG-AGAT and reverse ACTGCAGCCTCGAACTTCTG (180 bp); cIAP1/2, forward TTCCGTGGCTCTTATTCAAACT and reverse GCACAGTGGTAGGAACTTCTCAT (96 bp); 18sr, forward CCTGGATACCGCAGCTAGGA and reverse GCG GCGCAATACGAATGCCCC (112 bp). Amplification cycles were as follows: $95^{\circ} \mathrm{C}$ for $2 \mathrm{~min}$, then 40 cycles at $95^{\circ} \mathrm{C}$ for $15 \mathrm{~s}, 60^{\circ} \mathrm{C}$ for $1 \mathrm{~min}$, followed by $95^{\circ} \mathrm{C}$ for $10 \mathrm{~min}$, and $60^{\circ} \mathrm{C}$ for $1 \mathrm{~min}$. The fluorescent signal of the PCR product was detected by ABI PRISM ${ }^{\circledR} 7500$ Real-Time PCR System (Thermo Fisher Scientific, Inc.).

Statistical analysis. Statistical analysis was performed using SPSS version 19.0 (IBM SPSS, Armonk, NY, USA). Data are expressed as the mean \pm standard deviation of the mean. Student's t-test was applied to evaluate differences between the treated groups and controls. Data from multiple groups were analyzed using one-way analysis of variane, followed by the Tukey-Kramer multiple comparison test. For all tests, $\mathrm{P}<0.05$ was considered to indicate a statistically significant difference between groups.

\section{Results}

TNF- $\alpha$ sensitizes breast cancer cells to triptolide-induced cell death. The antiproliferative effects of the combination of TNF- $\alpha$ and triptolide against MDA-MB-231 and MCF-7 human breast cancer cells were examined using an MTT assay. As shown in Fig. 1, TNF- $\alpha$, at a low concentration of $10 \mathrm{ng} / \mathrm{ml}$, had no significant effects on cell proliferation of either human breast cancer cell lines. Exposure to different concentrations of triptolide (25-200 nM) with or without TNF- $\alpha$ for $24 \mathrm{~h}$ induced a dose-dependent inhibition in cell proliferation. As 
A

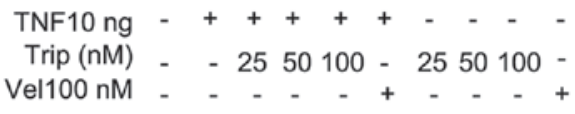

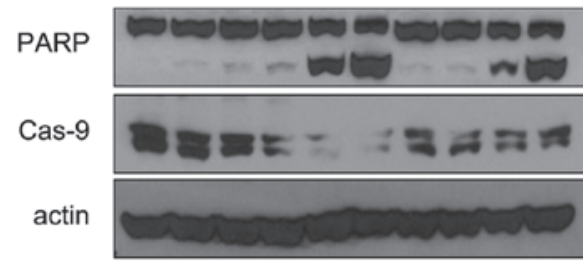

MDA-MB-231
B
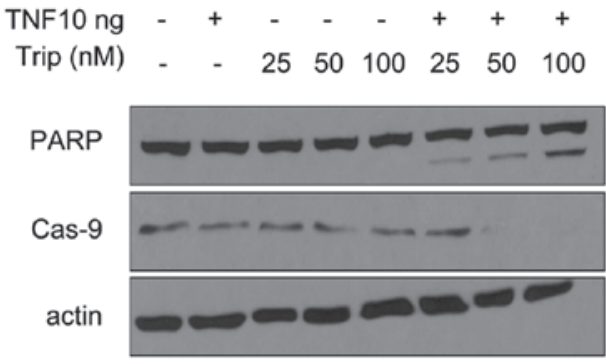

MCF-7

C

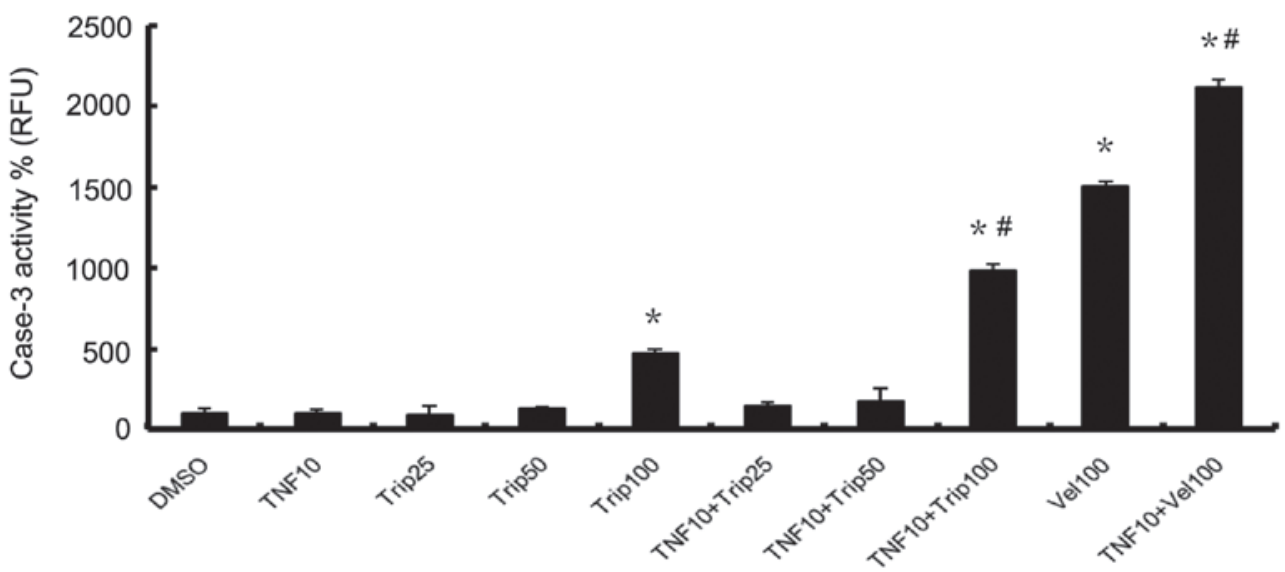

MDA-MB-231

Figure 2. Effects of different concentrations of triptolide in combination with TNF- $\alpha$ on PARP cleavage, and caspase-3 and -9 activity. The MDA-MB-231 cells and MCF-7 cells were treated either with different concentrations of triptolide, or with TNF- $\alpha$ (10 ng/ml)+different concentrations of triptolide, Velcade(100 nM) was used as a positive control. After $24 \mathrm{~h}$, the protein levels of PARP and caspase-9 were determined in the (A) MDA-MB-231 cells and (B) MCF-7 cells by Western blot analysis using specific antibodies. (C) Caspase-3 activity was determined in the MDA-MB-231 cells. Data are expressed as the mean \pm standard deviation of three experiments. $\mathrm{P}<0.05$, vs. DMSO-treated group; ${ }^{*} \mathrm{P}<0.05$ Trip/Vel-treated group, vs. Trip/Vel+TNF- $\alpha$ group. TNF- $\alpha$, tumor necrosis factor- $\alpha$; Trip, triptolide; DMSO-dimethyl sulfoxide; Vel, Velcade; PARP, poly (ADP-ribose) polymerase; Cas, caspase.

shown in Fig. 1A, triptolide exerted inhibitory effects when combined with or without TNF- $\alpha$, and the inhibitory effects were more marked in the combination group. The combination of TNF- $\alpha$ and triptolide exhibited increased cytotoxic effects against the MDA-MB-231 human breast cells at tripolide concentrations between 25 and $200 \mathrm{nM}$. The combined effects were not marked when a higher concentration of triptolide (400 nM) was used for treatment of the MDA-MB-231 cells. The combination treatment had decreased cytotoxic effects against the MCF-7 human breast cells (Fig. 1B), however, the combination of TNF- $\alpha$ and triptolide showed potent antiproliferative effects against the two human breast cancer cell lines.

TNF- $\alpha$ sensitizes breast cancer cells to triptolide-induced apoptosis. The present study then determined whether the cell death induced by TNF- $\alpha+$ triptolide corresponded to the apoptotic response. The MDA-MB-231 and MCF-7 cells were treated, respectively, with triptolide $(25,50$ and $100 \mathrm{nM})$, combined with or without TNF- $\alpha(10 \mathrm{ng} / \mathrm{ml})$ for $24 \mathrm{~h}$. The nuclear enzyme, PARP, which is one of the primary cleavage targets of caspase-3; and caspase-9, which activates caspase-3, were detected. Velcade, the first proteasome inhibitor to become a therapeutic modality for multiple myeloma, was used as a positive control, as it has been reported to induce the apoptosis of several types of cancer cell (14). As shown in Fig. 2A, TNF- $\alpha$, at a low concentration of $10 \mathrm{ng}$, markedly increased the effect of velcade on PARP cleavage. As shown in Fig. 2A and B, PARP cleavage was enhanced in the triptolide+TNF- $\alpha$-treated cells in a dose-dependent manner and, to a lesser degree, in the triptolide-treated cells. Triptolide also exhibited marked effects on the levels of caspase-9 in a dose-dependent manner. Caspase-9 decreased markedly when the concentration of triptolide reached $100 \mathrm{nM}$. Following treatment with TNF- $\alpha$ combined with triptolide, the degradation of caspase- 9 was more marked, compared with triptolide-only treatment in the two cell lines. As shown in Fig. 2C, a marked increase in caspase-3 activity was observed in the cells treated with TNF- $\alpha+$ triptolide, compared with the cells treated with triptolide alone, at triptolide concentrations up to $100 \mathrm{nM}$. Caspase-3 activity was not assessed in the MCF-7 cells, as MCF-7 cells do not express caspase-3. These data demonstrated that the combination of TNF- $\alpha$ and triptolide induced apoptosis in breast cancer cells, associated with the activation of caspase-3.

TNF- $\alpha$ sensitizes breast cancer cells to triptolide-induced apoptosis. The kinetic effects of the combination of TNF- $\alpha$ and triptolide were further evaluated in the present study. As shown in Fig. 3A and B, PARP fragments and caspase-9 reduction were not detected up to $24 \mathrm{~h}$ when treated with 
$\mathbf{A}$
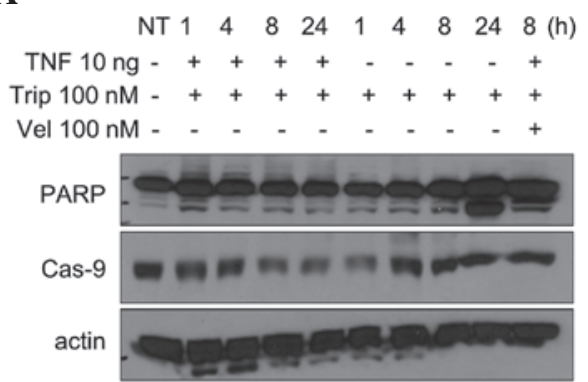

MDA-MB-231

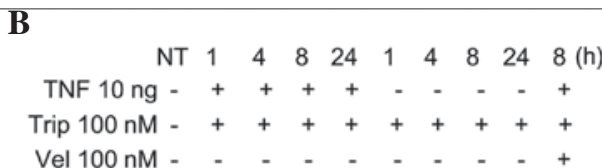

B

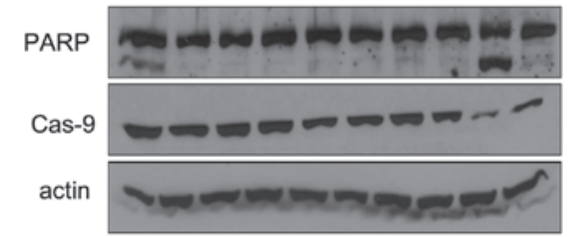

MCF-7

C

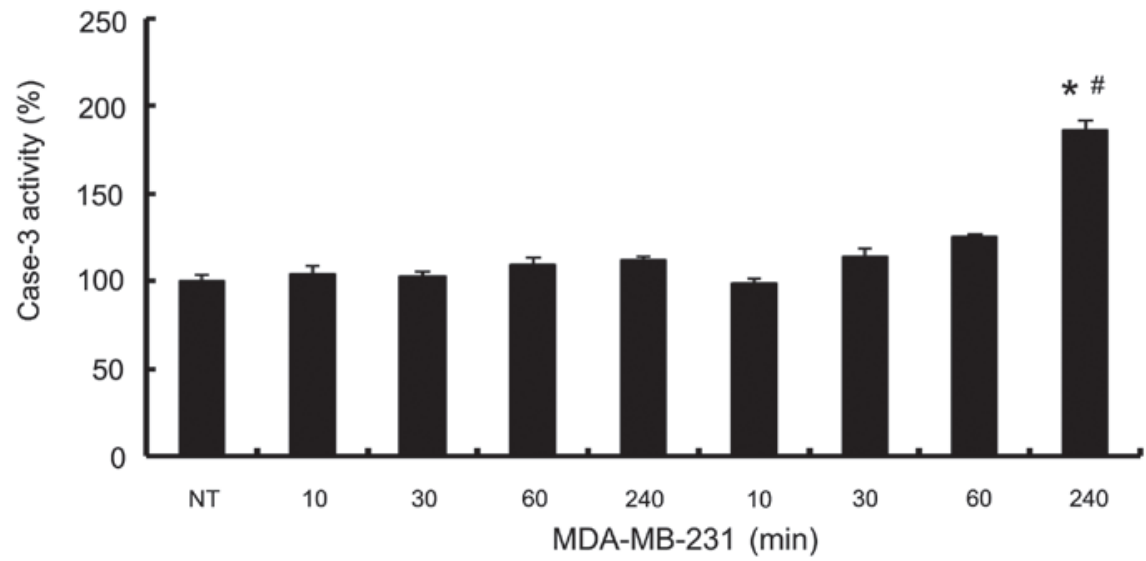

Figure 3. Kinetic effects of TNF- $\alpha+$ triptolide on PARP cleavage, and caspase-3 and -9 activities. The (A) MDA-MB-231 cells and (B) MCF-7 cells were treated with $100 \mathrm{nM}$ triptolide or with TNF- $\alpha(10 \mathrm{ng} / \mathrm{ml})+$ triptolide for the indicated durations. Velcade $(100 \mathrm{nM})$ was used as a positive control. The protein levels of PARP and caspase-9 were determined via Western blot analysis using specific antibodies. (C) Caspase-3 activity was determined in the MDA-MB-231 cells . Data are expressed as the mean \pm standard deviation of three experiments. ${ }^{*} \mathrm{P}<0.05$, vs. NT group; ${ }^{*} \mathrm{P}<0.05$ Trip/Vel-treated group, vs. Trip/Vel+TNF- $\alpha$ group. TNF- $\alpha$, tumor necrosis factor- $\alpha$; Trip, triptolide; NT, no treatment; Vel, Velcade; PARP, poly (ADP-ribose) polymerase; Cas, caspase.

A

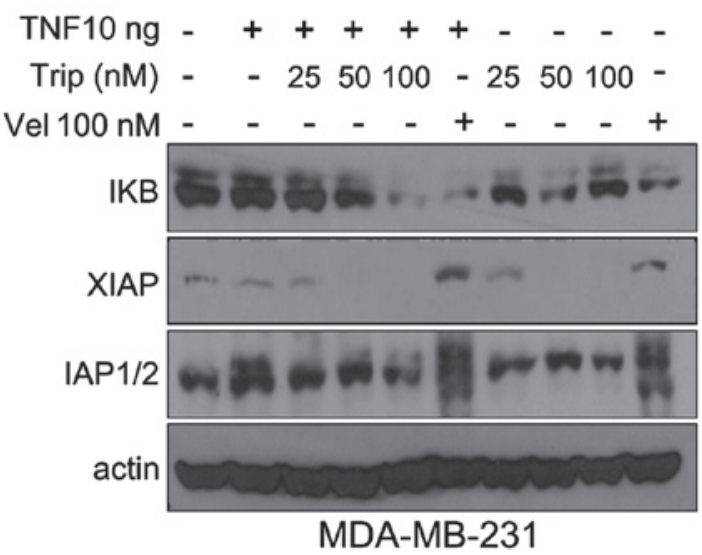

B

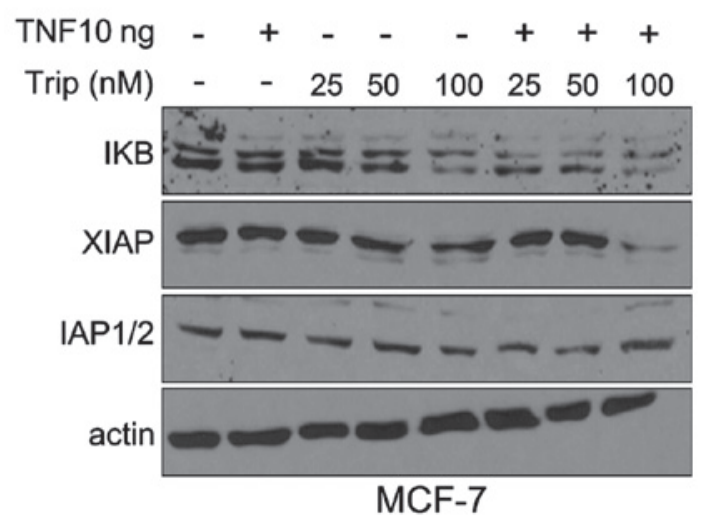

Figure 4. Effects of different concentrations of triptolide combined with TNF- $\alpha$ on the levels of NF- $\kappa$ B-targeting genes coding proteins. The (A) MDA-MB-231 and (B) MCF-7 cells were treated with either different concentrations of triptolide or with TNF- $\alpha$ (10 ng/ml)+different concentrations of triptolide, Velcade $(100 \mathrm{nM})$ was used as a positive control. After $24 \mathrm{~h}$, the protein levels of I $\mathrm{B}$, XIAP and cIAP1/2 were determined via Western blot analysis using specific antibodies. TNF- $\alpha$, tumor necrosis factor- $\alpha$; Trip, triptolide; Vel, Velcade; IKB; inhibitor of NF- $\kappa$ B; XIAP; X-linked inhibitor of apoptosis protein; IAP1/2, inhibitor of apoptosis protein $1 / 2$.

triptolide, with or without TNF- $\alpha$, in either of the cell lines. At $24 \mathrm{~h}$, the combination of TNF- $\alpha$ and triptolide markedly enhanced quantity of PARP fragments, and reduced the quantity of caspase-9 in the two cell lines, which were consistent with the results of Fig. 2. As shown in Fig. 3C, there were no changes in the caspase- 3 activity of the MDA-MB-231 cells prior to 240 mins when treated with triptolide alone, however, levels of activity increased at 240 mins when treated with TNF- $\alpha+$ triptolide. These data indicated that the combination of TNF- $\alpha$ with triptolide promoted the activation of caspase-3.

Effects of the combination of TNF- $\alpha$ with triptolide on the $N F-\kappa B$ pathway. Previous reports have demonstrated that triptolide is able to suppress the production of inflammatory 
A

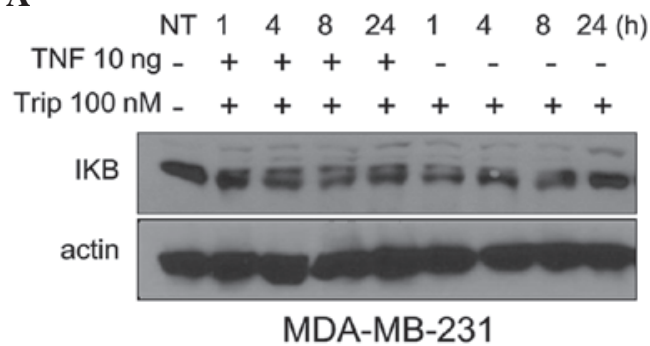

B

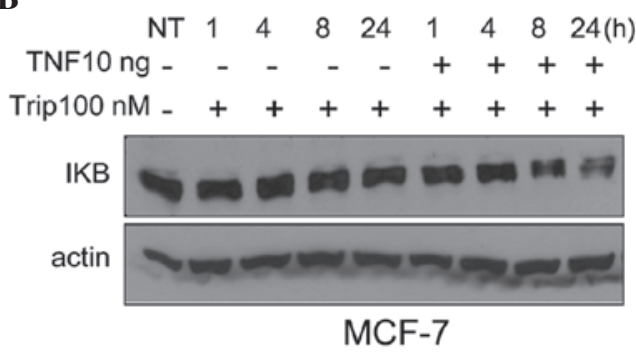

C

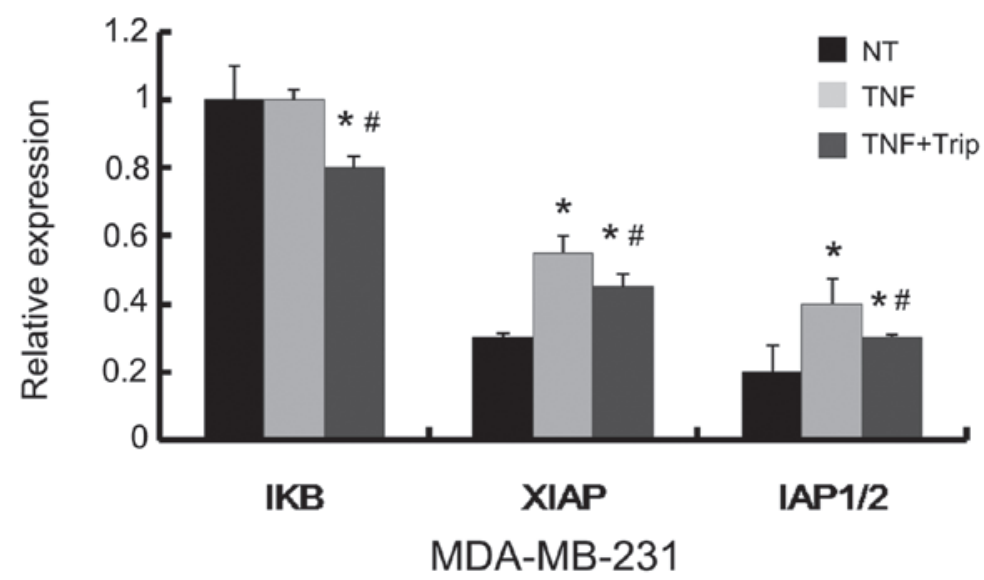

Figure 5. Kinetic effects of TNF- $\alpha+$ triptolide on the levels of I $\kappa$ B, and the mRNA levels of NF- $\kappa$ B-targeting genes. The (A) MDA-MB-231 cells and (B) MCF-7 cells were treated with $100 \mathrm{nM}$ triptolide, or with TNF- $\alpha(10 \mathrm{ng} / \mathrm{ml})+$ triptolidee $(100 \mathrm{nM})$ for the indicated durations. Velcade (20 nM) was used as a positive control. The protein levels of IкB, XIAP and cIAP1/2 were determined via Western blot analysis using specific antibodies. (C) MDA-MB-231 cells were treated with TNF- $\alpha(10 \mathrm{ng} / \mathrm{ml})$, or with TNF- $\alpha(10 \mathrm{ng} / \mathrm{ml})+$ triptolide $(100 \mathrm{nM})$ for $12 \mathrm{~h}$, followed by measurement of the mRNA levels of IкB, XIAP and cIAP1/2 via reverse transcription-quantitative polymerase chain reaction analysis. Data are expressed as the mean \pm standard deviation of three experiments. ${ }^{*} \mathrm{P}<0.05$, vs. NT group; ${ }^{*} \mathrm{P}<0.05$ Trip/Vel treated group, vs. Trip/Vel+TNF- $\alpha$ group. TNF- $\alpha$, tumor necrosis factor- $\alpha$; Trip, triptolide; Vel, velcade; NT, no treatment; IKB; inhibitor of NF- $\kappa \mathrm{B}$; XIAP; X-linked inhibitor of apoptosis protein; IAP1/2, inhibitor of apoptosis protein 1/2.

mediators induced by stimuli in various cell types $(5,12,15)$. As TNF- $\alpha$ and the NF-kB pathway are important in inflammation and are involved in the anti-inflammatory effect of

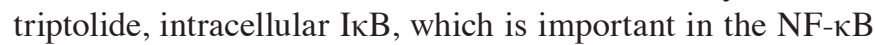
pathway was further examined. MDA-MB-231 and MCF-7 cells were treated, respectively, with triptolide $(25,50$ and $100 \mathrm{nM})$, with or without TNF- $\alpha(10 \mathrm{ng} / \mathrm{ml})$, for $24 \mathrm{~h}$. As shown in Fig. 4A and B, exposure of the cells to triptolide, either alone or with TNF- $\alpha$, inhibited the expression of IкB in a dose-dependent manner. This inhibitory effect was more marked when triptolide was used in combination with TNF- $\alpha$. The inhibitory effect of triptolide on IкB may be due to its inhibition of inflammatory pathways, which is consistent with previous reports $(11,12)$.

According to previous reports, XIAP and cIAP1/2 are target genes of NF- $\mathrm{KB}$ (16) and exert effects on the caspase-9 and caspase- 3 apoptotic pathways $(17,18)$. Therefore, the effects of TNF- $\alpha$ combined with triptolide on the levels of XIAP and cIAP $1 / 2$ were further examined in the present study. As shown in Fig. 4, in the MDA-MB-231 and MCF-7 cells, exposure to TNF- $\alpha$ and triptolide had no significant effect on the levels of cIAP1/2. However, triptolide caused a reduction in XIAP, and TNF- $\alpha$ aggravated these effects.

Time-dependenteffects of TNF- $\alpha+$ triptolideonI $\mathrm{KB}$. The present study also examined the kinetic effects of TNF- $\alpha$ +triptolide treatment on IкB. The MDA-MB-231 and MCF-7 cells were treated, respectively, with triptolide $(100 \mathrm{nM})$, with or without TNF- $\alpha(10 \mathrm{ng} / \mathrm{ml})$, and incubated for different durations. As shown in Fig. 5A and B, the levels of IкB and caspase-9 gradually decreased with increasing duration, and the decrease in the levels of IкB in the TNF- $\alpha+$ triptolide-treated cells were more marked, compared with those in the triptolide only-treated cells. The results of the kinetic effects confirmed that TNF- $\alpha$ combined with triptolide inhibited the expression of IкB and promoted the degradation of caspase-9.

Effects of TNF- $\alpha$ combined with triptolide on the transcription of $N F-\kappa B$ target genes. In order to investigate whether the inhibition of IкB, XIAP and IAP1/2 were caused by inhibiting gene expression, the mRNA expression levels of IкB, XIAP and IAP $1 / 2$ were analyzed using RT-qPCR. The MDA-MB-231 breast cancer cells were treated with TNF- $\alpha$ $(10 \mathrm{ng} / \mathrm{ml})$ or TNF- $\alpha+$ triptolide $(100 \mathrm{nM})$ for $6 \mathrm{~h}$. As shown in Fig. $5 \mathrm{C}$, TNF- $\alpha$ resulted in a marginal, but not significant increase in the mRNA level of IкB. This increase may be a feedback effect of the cells to TNF- $\alpha$. TNF- $\alpha+$ triptolide caused a significant decrease in the mRNA level of I $\kappa B$, which may have been due to inhibition of the NF- $\kappa B$ pathway by triptolide. The expression levels of XIAP and IAP $1 / 2$ increased when the MDA-MB-231 cells were treated with TNF- $\alpha$ alone. Treatment with TNF- $\alpha+$ triptolide reduced the expression levels of XIAP and IAP1/2, with the effects on XIAP being more marked, compared with the effects on IAP1/2. These 
results suggested that the inhibition of $\mathrm{I} \kappa \mathrm{B}, \mathrm{XIAP}$ and IAP1/2

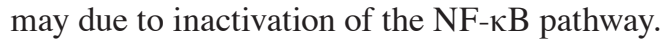

\section{Discussion}

Resistance to conventional chemotherapy and systemic toxicity remains a significant obstacle in improving the long-term survival rates of patients with breast cancer. Therefore, it is necessary to identify novel therapeutic strategies and agents to improve treatment. In the present study, it was demonstrated that a low dose of TNF- $\alpha$ sensitized MDA-MB-231 and MCF-7 cells to triptolide, leading to apoptosis. The results showed that treatment of cells with TNF- $\alpha$ (10 ng/ml) combined with triptolide (50-200 nM) increased triptolide-mediated cell death (Fig. 1), suggesting that low doses of TNF- $\alpha$ promoted triptolide to activate cell death. As shown in Fig. 2, TNF- $\alpha+$ triptolide activated caspase-3, and the activation of caspase- 3 coincided with an increase in the cleavage of PARP (Figs. 2 and 3). Caspase-3 led to activation of downstream events, and promoted cell apoptosis. These observations confirmed that combining TNF- $\alpha$ with triptolide may provide a novel therapeutic combination for the treatment of patients with breast cancer.

However, the mechanism underlying the combinational effect of TNF- $\alpha$ with triptolide to induce apoptosis remains to be fully elucidated. The response of cells to TNF- $\alpha$, an important modulator of $\mathrm{I} \kappa \mathrm{B}$, is key in the resistance to caspase-3-mediated apoptosis in several types of cancer cell $(2,3)$. I $\kappa \mathrm{B}$ is the predominant inhibitory protein of $N F-\kappa B$. Activation of $\mathrm{I} \kappa \mathrm{B}$ kinases (I $\kappa \mathrm{K} \alpha, \mathrm{I} \kappa \mathrm{K} \beta$ and the $\mathrm{NF}-\kappa \mathrm{B}$ essential modulator, I $\mathrm{K} \gamma$ ) results in phosphorylation of inhibitory $\mathrm{I} \kappa \mathrm{B} \alpha, \mathrm{I} \kappa \mathrm{B} \beta$ and $\mathrm{I} \kappa \mathrm{B} \varepsilon$ proteins bound to $\mathrm{NF}-\kappa \mathrm{B}$. NF- $\kappa \mathrm{B}$ is consequently released, and translocates to the nucleus where it interacts with other transcription factors and transcriptional co-factors to regulate the expression of an array of genes, several of which are involved in inflammatory signaling, proliferation and apoptosis (19). The classical activation of the NF- $\kappa \mathrm{B}$ pathway can be initiated by a wide range of extracellular stimuli. These agents can activate the cells and mediate the phosphorylation of $\mathrm{I} \kappa \mathrm{B}$, resulting in its degradation and rendering the $\mathrm{NF}-\kappa \mathrm{B}$ dimer-free to translocate to the nucleus to regulate several target genes (20), including XIAP/cIAP1/2 (21). NF- $\kappa \mathrm{B}$ is activated by a variety of pro-inflammatory agents, including TNF- $\alpha$, phorbol esters and several growth factors $(22,23)$. Of these agents, the tumor microenvironment has been implicated in TNF- $\alpha$-mediated $\mathrm{NF}-\kappa \mathrm{B}$ activation through the phosphorylation of $\mathrm{I} \kappa \mathrm{B}$. In the present study, it was found that triptolide significantly inhibited the level of I $\kappa \mathrm{B}$ induced by TNF- $\alpha$. Following the use of a low dose of TNF- $\alpha$ to imitate the tumor microenvironment, it was found that the combination of TNF- $\alpha$ and triptolide was more effective, compared with triptolide alone, at inhibiting the expression of I $\kappa \mathrm{B}$ (Fig. 4).

XIAP and cIAP-1/2 can inhibit death receptor-mediated apoptosis (24). These polypeptides belong to the IAP family, a group of intracellular proteins containing one or more zinc-binding baculovirus IAP repeat domains. Several IAPs, including XIAP, cIAP-1 and cIAP-2, also contain a carboxy-terminal RING domain with ubiquitin E3 ligase properties (25). Although all IAPs can potentially bind to caspases, only XIAP is a direct inhibitor of caspases-9, -3 and $-7(17,18)$, whereas cIAP-1 and cIAP-2 are considered to regulate receptor-mediated signaling pathways upstream of mitochondria, through their interactions with TNF receptor-associated factor (TRAF)1 and TRAF2 (26). The present study further examined the association between TNF- $\alpha$ with triptolide, and the levels of I $\mathrm{B}$, caspase-9, XIAP, and cIAP-1/2. The results demonstrated that $\mathrm{I} \kappa \mathrm{B}$, caspase-9, XIAP and $\mathrm{cIAP} 1 / 2$ were downregulated by the combination of TNF- $\alpha$ and triptolide in the breast cancer cells (Figs. 4 and 5). As XIAP is a direct inhibitor of caspases-9, -3 and $-7(17,18)$, the lower levels of XIAP and cIAP1/2, may contribute to the increased degradation of caspase-9. Therefore, the present study evaluated the effect of TNF- $\alpha$ combined with triptolide on the mRNA expression levels of I $\mathrm{B}, \mathrm{XIAP}$ and $\mathrm{cIAP} 1 / 2$. The results revealed that $\mathrm{TNF}-\alpha+$ triptolide markedly downregulates the mRNA levels of I $\mathrm{B}$, XIAP and cIAP1/2 in the breast cancer cells (Fig. 5A). This downregulation of $\mathrm{I} \kappa \mathrm{B}$ eliminated the activation of the NF- $\kappa \mathrm{B}$-pathway that was induced by TNF- $\alpha$. In the presence of a low dose of TNF- $\alpha$, the suppressive effects of triptolide on XIAP and cIAP1/2 became necessary for the apoptotic pathway to facilitate caspase-3 activation.

In conclusion, the present study found that the cytotoxic effects of triptolide on breast cancer cells were enhanced in the presence of TNF- $\alpha$. The investigation of TNF- $\alpha$ in the tumor microenvironment revealed that the levels of TNF- $\alpha$ are generally higher in the tumor microenvironment, and that TNF- $\alpha$ is important in the development of tumors. The results of the present study provided evidence for the effect of the natural anti-inflammatory drug, triptolide, in the treatment of inflammatory tumors, which holds important implications for the therapeutic strategies used in the treatment of breast cancer.

\section{Acknowledgements}

This study was supported by grants from the National Natural Science Foundation of China (grant no. 81101747 to Dr Li Lu and grant no. 81372855 to Dr Gui Hi Wang).

\section{References}

1. Labovsky V, Martinez LM, Davies KM, García-Rivello H, Calcagno Mde L, Matas A, Fernández Vallone VB, Wernicke A, Choi $\mathrm{H}$ and Chasseing NA: Association between ligands and receptors related to the progression of early breast cancer in tumor epithelial and stromal cells. Clin Breast Cancer 15: e13-e21, 2015.

2. Sung B, Park B, Yadav VR and Aggarwal BB: Celastrol, a triterpene, enhances TRAIL-induced apoptosis through the down-regulation of cell survival proteins and up-regulation of death receptors. J Biol Chem 285: 11498-11507, 2010.

3. Mandal C, Dutta A, Mallick A, Chandra S, Misra L, Sangwan RS and Mandal C: Withaferin A induces apoptosis by activating p38 mitogen-activated protein kinase signaling cascade in leukemic cells of lymphoid and myeloid origin through mitochondrial death cascade. Apoptosis 13: 1450-1464, 2008.

4. Kang DW, Lee JY, Oh DH, Park SY, Woo TM, Kim MK, Park MH, Jang YH and Min do S: Triptolide-induced suppression of phospholipase D expression inhibits proliferation of MDA-MB-231 breast cancer cells. Exp Mol Med 41: 678-685, 2009.

5. Chen BJ: Triptolide, a novel immunosuppressive and anti-inflammatory agent purified from a Chinese herb Tripterygium wilfordii Hook F. Leuk Lymphoma 42: 253-265, 2001.

6. Wu WY and Wang YP: Pharmacological actions and therapeutic applications of Salvia miltiorrhiza depside salt and its active components. Acta Pharmacol Sin 33: 1119-1130, 2012. 
7. Kiviharju TM, Lecane PS, Sellers RG and Peehl DM: Antiproliferative and proapoptotic activities of triptolide (PG490), a natural product entering clinical trials, on primary cultures of human prostatic epithelial cells. Clin Cancer Res 8: 2666-2674, 2002.

8. Fidler JM, Li K, Chung C, Wei K, Ross JA, Gao M and Rosen GD: PG490-88, a derivative of triptolide, causes tumor regression and sensitizes tumors to chemotherapy. Mol Cancer Ther 2: 855-862, 2003

9. Yang S, Chen J, Guo Z, Xu XM, Wang L, Pei XF, Yang J, Underhill CB and Zhang L: Triptolide inhibits the growth and metastasis of solid tumors. Mol Cancer Ther 2: 65-72, 2003.

10. Tengchaisri T, Chawengkirttikul R, Rachaphaew N, Reutrakul V, Sangsuwan R and Sirisinha S: Antitumor activity of triptolide against cholangiocarcinoma growth in vitro and in hamsters. Cancer Lett 133: 169-175, 1998.

11. Liu H, Liu ZH, Chen ZH, Yang JW and Li LS: Triptolide: A potent inhibitor of NF-kappa B in T-lymphocytes. Acta Pharmacol Sin 21: 782-786, 2000.

12. Lu L, Kanwar J, Schmitt S, Cui QC, Zhang C, Zhao C and Dou QP: Inhibition of tumor cellular proteasome activity by triptolide extracted from the Chinese medicinal plant 'thunder god vine'. Anticancer Res 31: 1-10, 2011.

13. Yang H, Shi G and Dou QP: The tumor proteasome is a primary target for the natural anticancer compound Withaferin A isolated from 'Indian winter cherry'. Mol Pharmacol 71: 426-437, 2007

14. Perrone G, Hideshima T, Ikeda H, Okawa Y, Calabrese E, Gorgun G, Santo L, Cirstea D, Raje N, Chauhan D, et al: Ascorbic acid inhibits antitumor activity of bortezomib in vivo. Leukemia 23: 1679-1686, 2009.

15. Zhao G, Vaszar LT, Qiu D, Shi L and Kao PN: Anti-inflammatory effects of triptolide in human bronchial epithelial cells. Am J Physiol Lung Cell Mol Physiol 279: L958-L966, 2000.

16. Sethi G, Ahn KS and Aggarwal BB: Targeting nuclear factor-kappa B activation pathway by thymoquinone: Role in suppression of antiapoptotic gene products and enhancement of apoptosis. Mol Cancer Res 6: 1059-1070, 2008.
17. Eckelman BP, Salvesen GS and Scott FL: Human inhibitor of apoptosis proteins: Why XIAP is the black sheep of the family. Embo Rep 7: 988-994, 2006.

18. Srinivasula SM, Hegde R, Saleh A, Datta P, Shiozaki E, Chai J, Lee RA, Robbins PD, Fernandes-Alnemri T, Shi Y and Alnemri E: A conserved XIAP-interaction motif in caspase-9 and Smac/DIABLO regulates caspase activity and apoptosis. Nature 410: 112-116, 2001.

19. Baeuerle PA and Baltimore D: NF-kappa B: Ten years after. Cell 87: 13-20, 1996.

20. Zhao Y, Fu Y, Hu J, Liu Y and Yin X: The effect of tissue factor pathway inhibitor on the expression of monocyte chemotactic protein-3 and IкB- $\alpha$ stimulated by tumour necrosis factor- $\alpha$ in cultured vascular smooth muscle cells. Arch Cardiovasc Dis 106: 4-11, 2013.

21. Gyrd-Hansen M and Meier P: IAPs: From caspase inhibitors to modulators of NF-kappaB, inflammation and cancer. Nat Rev Cancer 10: 561-574, 2010.

22. Takada Y, Singh S and Aggarwal BB: Identification of a p65 peptide that selectively inhibits NF-kappa B activation induced by various inflammatory stimuli and its role in down-regulation of NF-kappaB-mediated gene expression and up-regulation of apoptosis. J Biol Chem 279: 15096-15104, 2004.

23. Vile GF, Tanew-Ilitschew A and Tyrrell RM: Activation of NF-kappa B in human skin fibroblasts by the oxidative stress generated by UVA radiation. Photochem Photobiol 62: 463-468, 1995.

24. Varfolomeev E, Goncharov T, Fedorova AV, Dynek JN Zobel K, Deshayes K, Fairbrother WJ and Vucic D: c-IAP1 and c-IAP2 are critical mediators of tumor necrosis factor alpha (TNFalpha)-induced NF-kappaB activation. J Biol Chem 283: 24295-24299, 2008.

25. Salvesen GS and Duckett CS: IAP proteins: Blocking the road to death's door. Nat Rev Mol Cell Biol 3: 401-410, 2002.

26. Rothe M, Pan MG, Henzel WJ, Ayres TM and Goeddel DV: The TNFR2-TRAF signaling complex contains two novel proteins related to baculoviral inhibitor of apoptosis proteins. Cell 83: $1243-1252,1995$ 